\title{
Social Context in Developmental Psychopathology: Recommendations for Future Research from the MacArthur Network on Psychopathology and Development
}

\section{Citation}

Boyce, W. Thomas, Ellen Frank, Peter S. Jensen, Ronald C. Kessler, Charles A. Nelson, and Laurence Steinberg. 1998. Social Context in Developmental Psychopathology: Recommendations for Future Research from the MacArthur Network on Psychopathology and Development. Development and Psychopathology 10, no. 2: 143-164.

\section{Published Version}

doi:10.1017/S0954579498001552

\section{Permanent link}

http://nrs.harvard.edu/urn-3:HUL.InstRepos:12997516

\section{Terms of Use}

This article was downloaded from Harvard University's DASH repository, and is made available under the terms and conditions applicable to Other Posted Material, as set forth at http:// nrs.harvard.edu/urn-3:HUL.InstRepos:dash.current.terms-of-use\#LAA

\section{Share Your Story}

The Harvard community has made this article openly available.

Please share how this access benefits you. Submit a story. 


\title{
Social context in developmental psychopathology: Recommendations for future research from the MacArthur Network on Psychopathology and Development
}

\author{
W. THOMAS BOYCE, ${ }^{a}$ ELLEN FRANK,${ }^{b}$ PETER S. JENSEN, ${ }^{c}$ \\ RONALD C. KESSLER, ${ }^{d}$ CHARLES A. NELSON,${ }^{e}$ LAURENCE STEINBERG ${ }^{f}$ \\ AND THE MACARTHUR FOUNDATION RESEARCH NETWORK ON \\ PSYCHOPATHOLOGY AND DEVELOPMENT \\ ${ }^{a}$ University of California, Berkeley; ${ }^{b}$ University of Pittsburgh; ${ }^{c}$ National Institute of \\ Mental Health; ${ }^{d}$ Harvard University; ${ }^{e}$ University of Minnesota; and ${ }^{f}$ Temple University
}

\begin{abstract}
Accumulating evidence suggests that social contexts in early life have important and complex effects on childhood psychopathology. Spurred by the lack of an explicit operational definition that could guide the study of such effects, we define a social context operationally as "a set of interpersonal conditions, relevant to a particular behavior or disorder and external to, but shaped and interpreted by, the individual child." Building on this definition, we offer a series of recommendations for future research, based on five theoretically derived propositions: (a) Contexts are nested and multidimensional; (b) contexts broaden, differentiate, and deepen with age, becoming more specific in their effects; (c) contexts and children are mutually determining; (d) a context's meaning to the child determines its effects on the child and arises from the context's ability to provide for fundamental needs; and (e) contexts should be selected for assessment in light of specific questions or outcomes. As reflected in an increasingly rich legacy of literature on child development and psychopathology, social contexts appear to influence emerging mental disorders through dynamic, bidirectional interactions with individual children. Future research will benefit from examining not only statistical interactions between child- and context-specific factors, but also the actual transactions between children and contexts and the transduction of contextual influences into pathways of biological mediation. Because adverse contexts exert powerful effects on the mental health of children, it is important for the field to generate new, more theoretically grounded research addressing the contextual determinants of psychological well-being and disorder.
\end{abstract}

Since many of the most disabling psychiatric disorders begin in childhood, an understanding of psychopathology in children and adolescents is an essential requirement for the creation of new and specific interventions for neuropsychiatric syndromes. Approaches that

This work was sponsored by the John D. and Catherine T. MacArthur Foundation. We are grateful to Professor Richard Jessor for his helpful and insightful critique of an earlier draft of this manuscript.

Address correspondence and reprint requests to: W. Thomas Boyce, Division of Health and Medical Sciences, School of Public Health, University of California, 570 University Hall, \#1190, Berkeley, CA 94720-1190. provide conceptual and methodologic tools for integrating the psychosocial and biological influences on early development are also critical to constructing models of psychiatric disease onset. In an effort to advance a broader and more general understanding of how environments exert effects on mental disorder and how "context" might best be conceptualized and defined, this paper addresses the construct of "social context" in the field of developmental psychopathology.

Psychosocial problems affecting the lives and health of U.S. children are arguably as prevalent and serious today as they have ever 
been. Nearly 13 million U.S. children live in poverty, with young people less than 18 years of age constituting the single most impoverished demographic group in the nation (Bane \& Ellwood, 1989; U.S. Department of Health and Human Services, 1990a). AfricanAmerican and Hispanic children, moreover, are two to three times more likely to be impoverished than White children (U.S. House of Representatives Select Committee on Children, 1989). Over one third of children experience a parental divorce (Solomon \& Wallerstein, 1994), and approximately $25 \%$ live in single parent homes (Richmond, 1990). More than one million cases of child abuse or neglect are confirmed per year, and between 3 and 10 million children are exposed annually to domestic violence (Children's Defense Fund, 1995). The social environments in which many children now live offer minimal support for healthy emotional development and are often openly and multiply aversive.

As if these longstanding threats to the well-being of children were not sufficiently disquieting, more recent social changes have produced issues of equal or even greater concern. An estimated 1.2 million families are on waiting lists for public housing, and one in four persons reported as homeless is a child younger than 18 years of age (Children's Defense Fund, 1995). The annual number of runaway youths is approximately one million (U.S. House of Representatives Select Committee on Children, 1989), and nearly 2.1 million children between the ages of 5 and 13 have no adult to care for them after school (U.S. House of Representatives Select Committee on Children, 1989). A rise in parental substance abuse has affected the biological or emotional development of as many as one fifth to one third of inner city newborns (Frank et al., 1988), and the escalation of violence in urban neighborhoods has become an urgent public health concern (Koop \& Lundberg, 1992).

Perhaps related to these troubling forces in the environments of the nation's children, childhood mental disorders have become increasingly prevalent and compelling problems. Recent studies suggest that between 17 and 22\% of children (approximately 11-14 million) have mental disorders meeting DSM criteria (U.S. Department of Health and Human Services, 1990b). Affective, conduct, and anxiety disorders, which together comprise the largest proportion of childhood psychiatric disturbances, often produce adaptive difficulties in the teenage years and, particularly in girls, lead to chronic mental health disorders in adult life (Institute of Medicine, 1989; U.S. Department of Health and Human Services, 1990b). Further, data from the 1988 National Health Interview Survey reveal that $4 \%$ of U.S. children have developmental delays, $6.5 \%$ learning disabilities, and $13.4 \%$ emotional or behavioral disorders, leading Zill and Schoenborn (1990) to conclude that "psychological disorders rank among the most prevalent health conditions of modern childhood."

The declining economic, material, and social environments in which contemporary children are raised have almost certainly played an etiologic role in the escalation of childhood mental disorders (Jensen, Richters, Ussery, Bloedau, \& Davis, 1991). As a result, investigators in the field of developmental psychopathology have focused attention on the ways in which social environmental forces interact with children's biology to shape actively the emergence of psychopathology in early development (Bornstein, 1995; Harris, 1995; Hiday, 1995). While there is new recognition of biological-genetic factors in the etiology of mental disorder, there is also evidence that constitutional elements seldom act in isolation, and that interactions between biology and psychosocial factors often have greater explanatory power in the prediction of psychopathology (Sameroff, 1983). Jensen et al. (1993) thus summarized research needs emanating from the 1990 National Plan for Research on Child and Adolescent Mental Disorders by highlighting the importance of relationships and social environments as determinants of child and adolescent psychopathology.

\section{Purpose}

The publication of this Special Issue of Development and Psychopathology provides a timely opportunity to review, synthesize, and 
elaborate upon several dominant themes emerging over the recent past in research on context and psychopathology. The past two decades, in particular, have witnessed important shifts in the ways researchers conceptualize, assess, and study the settings in which children grow and psychopathology develops. Owing to the empirical work of such scholars as Belsky (1988), Cicchetti (1993), Garmezy (Garmezy, Masten \& Tellegen, 1984), Patterson (1982), Rutter (1990), Sameroff (1983), and Sroufe (1989), among others, and drawing on the theoretical perspectives of those such as Baltes (1997), Bronfenbrenner (1979), Lewin (1951), and Minuchin (1974), the study of psychopathology and development has been transformed from one focused on the "afflicted" individual, into a field that examines transactions between developing individuals and the complex, multilayered environments in which they live.

Our purpose in this paper is not to review the immense literature on contextual influences in psychopathology, a literature that has burgeoned over the last 20 years. Indeed, such a review would be beyond the reasonable scope of a single volume, much less a single article. Rather, our intent here is to integrate and draw readers' attention to a collection of central assertions about the role of context in the development of psychopathology. We have tried to approach that objective in a manner that acknowledges the ideas undergirding this emerging focus (e.g., Cicchetti \& Richters, 1997; Goldsmith, Gottesman, \& Lemery, 1997; Kagan, 1997; Rutter et al., 1997; Sroufe, 1997), that provides ready reference for researchers unfamiliar with these intellectual developments, and that marks a starting point for a new generation of research on contexts and psychopathology. Our hope is that this integrative summary will both codify a set of guiding propositions and stimulate further empirical and theoretical work grounded within them.

Both an apologia and an apology are in order before turning to the business at hand. With respect to the former, our attempt to summarize familiar, yet fundamental, tenets that have emerged over a span of years, and that undergird contemporary study of child psychopathology, may prompt some readers to view our work as preaching to the converted. While we recognize that some will find some of the article's content to be old news, we nonetheless believe that there is considerable value in an occasional stock-taking, if chiefly for the benefit of those readers whose familiarity with the field is either limited or uneven. Indeed, only cursory examination of research published in many current and credible scholarly journals reveals that some of the principles assumed to be common knowledge are, in fact, not universally adhered to by the majority of practicing investigators. Thus, one of our hopes is that this publication will help turn common knowledge into common practice. As to the apology, the brevity of this article, especially in relation to the size of the field, necessitates that our discussion of specific research be illustrative, not exhaustive. The particular studies chosen to illustrate the general points we raise were selected because they are good examples of the principles we advocate, not because they are the only examples. We apologize, in advance, to the many researchers whose exemplary work our discussion appears to ignore.

\section{Themes and Definition}

While interest in and appreciation for the influences of early psychosocial environments have grown in recent years, a significant proportion of research on childhood psychopathology has proceeded without a unifying framework for conceptualizing and operationalizing the relations among environmental factors, child development, and psychopathology. More specifically, the absence of a conceptual and operational definition of the term context can lead to misunderstanding when less developmentally guided investigators, in an effort to be comprehensive, assess as many known contextual risk factors for child psychopathology as possible. In this sense, context is often used as a form of jargon for anything environmental, as if invoking the term suggests compliance with current scientific and conceptual canons. The inexact use of such terms and the accumulation of findings without a guiding conceptual framework can become, however, 
a cacophony of uninterpretable observations. We therefore offer an approach to conceptualizing and operationalizing social context and present a series of recommendations for future research, in an effort to lend increased coherence to the flourishing literature on psychopathology in development.

Implicit within our proposals are several key themes that have guided our thinking in this work. First, we believe that, while an exhaustive consideration of environmental influences is beyond the scope of any study, a set of general principles can be articulated that can guide investigators' selection of critical social-psychological factors and contextual constructs within a given area of research. These principles, presented as five propositions, are discussed in detail below. Second, while we emphasize the importance of understanding children's social contexts in our proposal, we do not in any way suggest that the effects of social-psychological factors on children's development are fully separable or independent from a child's unfolding biologic substrate. Such simplistic assumptions are contradicted by the burgeoning literature on social environments and brain development (Cicchetti \& Tucker, 1994; Eisenberg, 1995; Nelson \& Bloom, 1997), and by recent evidence for interactions between social environments and genetically regulated endogenous factors (e.g., Boyce et al., 1995).

Finally, we believe that antecedent social environmental experiences significantly influence and are incorporated into later developmental structures and functions (Erikson, 1963). Heritable and early experiential influences, interpreted by the child and transcribed into individual biology in the form of memory traces and neural processes, are brought forward in time into dynamic interactions with new experience, as the child interprets, acts upon, and is affected by these new experiences. Such interactions result in the elaboration of increasingly distinct and differentiated developmental outcomes.

For the purposes of the present paper, we offer the following operational definition of social context for future studies of child psychopathology: A social context is a set of interpersonal conditions, relevant to a particular behavior or disorder and external to, but shaped and interpreted by, the individual child. So defined, social contextual factors help us to understand for whom, or under what conditions, a given outcome will hold. Contexts inherently imply contingencies, in that they describe the circumstances or settings in which individual predispositions may emerge and become visible. Additionally, this definition of context emphasizes the transactional nature of individual-environment interaction; put most simply, contexts affect individuals and individuals affect contexts (Sameroff, 1983). Further, our definition of social context implies a universal placement of persons, objects, and events into a frame of reference from which interpretation and meaning are derived (Cole, 1995). With these defining conditions specified, we offer five strategic propositions, together comprising our recommendations for the treatment of social context in future research within developmental psychopathology.

\section{Proposition 1: Contexts are nested and multidimensional}

Although the literature on psychopathology in childhood has frequently investigated social environmental influences on the development of disorder, many studies have been relatively narrow in scope. While there are important exceptions to this empirical shortcoming (e.g., Belsky \& Rovine, 1988; Cairns \& Cairns, 1994; Conger, Ge, Elder, Lorenz, \& Simons, 1994; Patterson, 1982), and while many writers acknowledge the need for more complex studies of the interplay among settings, even a cursory review of the research published in many leading clinical psychology and psychiatry journals indicates that context often consists of a single setting, the child's family, and within that setting, only one dimension is typically examined. Interestingly, this description is less characteristic of research on normative development, which has been faster than research on psychopathology to embrace the ecological approach articulated by Bronfenbrenner (1986b), Sameroff (1983), and others. Jessor (1993) has called attention to this "tra- 
ditional preoccuption with intrafamilial interactions" in the study of psychopathology and suggests the need for new and broader scientific attention to extrafamilial transactions. Further, even when multiple settings are considered, examination of contextual effects in many studies of childhood psychopathology may resemble a simple "laundry list" of environmental risk factors for various disorders, rather than an integrative understanding of the processes through which complex environments and developing children interact over time. Thus, studies that simply rely upon multiple regression approaches to examining the presumed linear, additive effects of multiple environmental factors on child outcomes may not sufficiently advance our understanding of how unique and specific combinations of social-psychological factors shape the outcomes of individual children. Alternative research approaches would carefully assesses the conditions under which these relations do and do not apply, while simultaneously incorporating the child's, family's, and/or community's attribution of meaning to these social-psychological factors.

In our view, several specific changes in perspective would advance research on the role of social context in psychopathological development. First, investigators could take into account more systematically the multidimensionality of contextual influence. For example, within any given environment in which children develop, an investigator may identify one or more particular environmental dimensions as a focus for study in relation to one or more outcome variables. Once these are identified, the investigator can then examine the relations among two or more social environmental dimensions and the conditions under which the purported relations among contextual factors apply to specific outcomes. Thus, a study of familial influences on the development of childhood anxiety might examine the contingent and interactive roles of marital conflict (e.g., Cummings, Ballard, El-Sheikh, \& Lake, 1991), parental intrusiveness (e.g., Stark, Humphrey, Cook, \& Lewis, 1990), or maternal depression (e.g., Rutter, 1990). Similarly, a study of the role of socialpsychological factors in the development of externalizing problems might examine the convergent and divergent impacts of disciplinary laxity (Patterson, 1986), parent criminality (Farrington \& West, 1991), or harsh parenting (Conger et al., 1994), and peer/ neighborhood influences. While investigations of single aspects of the environment may be informative, they are likely to be only partially so. As Bronfenbrenner (1979) has pointed out, any given context has multiple dimensions, and these dimensions are likely to interact with one another in etiologically important ways.

Given measurement of any two hypothesized contextual factors, three general models of multidimensional influence may be identified: additive models, moderated models, and mediated models (Baron \& Kenny, 1986). Consider, as a specific example, the effects of parental emotional rejection and lax discipline, both of which have been independently documented as risk factors for psychological disorder in children (Becker, 1962; Blumenthal \& Kupfer, 1988; Miller, Cowan, Cowan, Hetherington, \& Clingempeel, 1993; Patterson \& Stouthamer-Loeber, 1984; Petersen et al., 1993). On the one hand, additive models would assume that both parental rejection and lax discipline increase childhood psychopathology, with each factor elevating the risk for disorder to the same degree in isolation as they do when present in combination. On the other hand, one might find that the two factors function interactively, so that the effect of lax discipline on psychopathology is diminished under conditions of parental acceptance but amplified under conditions of parental rejection (a moderated model). Yet a third possibility is that the effect of one variable is mediated entirely through a process involving the other. For example, parental rejection could elevate the risk for psychopathology, because rejection leads to lax discipline, which in turn promotes psychological dysfunction. The specific examples are less important than the general point: Contexts have multiple dimensions that add to, moderate, and mediate one another in influencing children's behavioral and emotional development.

Second, research may benefit from investigators differentiating more clearly between 
structural versus functional aspects of contexts. Structural aspects refer to the organization and composition of the hierarchical elements that define a context, what Bronfenbrenner (1979) has called the setting's "social address," whereas functional aspects refer to transactional processes that take place between those elements. Conceptual problems typically arise when a researcher has a theory about the impact of functional variables on psychopathology (e.g., the impact of parental monitoring on childhood conduct disorder), but is in actuality studying structural, not functional, variables. Thus, marital status (e.g., whether a child's parents are married, divorced, or remarried) may be used as a proxy for parenting practices (e.g., how strict the parent is with the child), or a mother's employment status may be used as a substitute for a measure of mother-child interaction. A reasonable hypothesis is that the impact of the structural characteristics of a setting on the psychological development of the child is mediated through one or more functional characteristics of the setting. If marital status does affect child psychopathology, for example, it likely does so through its impact on aspects of family functioning (the parent-child relationship, the marital relationship, etc.) (e.g., Fauber, Forehand, McCombs, \& Wierson, 1990) or the child's attributions about the meaning of particular marital status categories in comparison with the larger peer milieu.

Third, as much as possible, research on contextual effects may be enhanced by an examination of interactions among contexts and the ways in which multiple settings influence each other in affecting child development. In Bronfenbrenners (1979) model of the ecology of human development, studies of the interrelations among contexts and their joint impacts on development are referred to as studies of the "meso-system." Addressing the role of cultural-historical contexts in child development, Cole (1992) invoked two images of such contextual interrelations. In one, successively broader social contexts form concentric circles around an individual child, each circle serving as a larger context for the more proximal ones. In a second analogy, the dynamic exchanges among contexts are envisioned as a rope or cord, woven together by different strands of interacting contextual influence occurring over time.

As an example of such contextual interactions, consider the relations among familial factors, peer factors, and disorders of conduct. In one hypothetical model, we might predict that both lax discipline in the home and association with deviant peers contribute independently to children's behavior problems. Children exposed to both risk factors would therefore be more likely to develop behavior problems than children exposed to only one. An alternative account might be developed, however, in which externalizing problems are associated with lax parental discipline only when the child has contact with antisocial peers. In either case, a research design that focused on only a single setting might reveal important information about its contribution to conduct problems, but would account for only part of the story.

Studies that consider only one environmental setting (e.g., home, school, or neighborhood) are limited, then, in their capacity to illuminate processes occurring over time, through which multiple settings may be linked to psychopathology. This point is illustrated in a series of studies by Patterson and his colleagues on the joint influence of parents and peers on adolescent misbehavior (e.g., Dishion, Patterson, Stoolmiller, \& Skinner, 1991). According to their findings, ineffective discipline in the home leads children to affiliate with antisocial peers, which increases the risk of engaging in misbehavior. In this instance, the link between experiences in one context (the family) and psychopathology is mediated through experiences in a second setting (the peer group).

Finally, studies will be enriched by recognizing the embeddedness of contexts. Proximal settings (e.g., the family) are nested within broader settings (e.g., communities), which moderate the influences of proximal processes. The proximal social contexts considered in the preceding example, the family and peer group, are embedded in a broader context that contains them, shapes them, links them to each other, and moderates their independent and joint influences on a child's de- 
velopment. This broader context is composed of the neighborhood, community, culture, and historical epoch in which the child lives. Remarkably little is known about how these broader contexts affect the development or expression of psychopathology.

One welcome trend in the exploration of the larger contexts of children's lives and their implications for psychological dysfunction is reflected in the growth of research on neighborhood and community factors in child and adolescent development (e.g., BrooksGunn, Duncan, \& Aber, 1995; Sampson \& Laub, 1994). Rooted in sociological studies of urban neighborhoods during the 1930s and 1940s (e.g., Faris \& Dunham, 1939), this research is examining how structural characteristics of communities (e.g., unemployment, racial mix, and crime rates) affect children's internalizing and externalizing problems through effects on the behavior of families and peer groups. Some community effects are direct; for example, repeated exposure to violence is likely to elevate children's levels of depression, anxiety, and fear (Fitzpatrick, 1993). Other community effects are mediated through influences on proximal environments; thus, crime in a community may heighten parents' protectiveness to the point of restricting the development of autonomy and independence (Elder \& Ardelt, 1992; McCarthy, Lord, Eccles, Kalil, \& Furstenberg, 1992). Finally, some community effects operate by moderating processes that occur within more immediate settings. For example, the relation between certain parenting practices, such as parental authoritativeness, and children's mental health may vary as a function of features of the neighborhood, such as the proportion of other authoritative families (Darling \& Steinberg, 1993).

Recommendations. Research on the role of social contexts in childhood psychopathology may benefit from consideration of the following issues:

- the multidimensionality of social-psychological influences within and across hierarchical levels of children's environments,
- the relative merits of choices between structural and functional measures within a given social context,

- the possible additive, mediating, and moderating relations among social-psychological factors at different hierarchical levels, and

- the embeddedness of each context in a broader social milieu and the influence of distal contexts on more proximal settings and processes.

While no study can or should address every plausible context and contextual dimension of influence, it will be important in future work to consider the complexity and interrelatedness of multiple, hierarchically ordered contextual systems. Among the many issues in need of further research are (a) the ways in which cultural variation in concepts of normal child development affect the definition and identification of various childhood disorders (e.g., Weisz et al., 1993); (b) the role of broader economic factors (such as unemployment) in the development of childhood disturbance (e.g., Brody et al., 1994; Conger et al., 1994; McLoyd, 1990a; Sampson \& Laub, 1994; Steinberg, Catalano, \& Dooley, 1981); and (c) historical factors that influence the prevalence and expression of childhood psychopathology (e.g., Lewinsohn, Rohde, Seeley, \& Fischer, 1993).

Proposition 2: Contexts broaden, differentiate, and deepen with age, becoming more specific in their effects

Social contexts change over time in response to a child's growth, development, or disorder, to changes in other setting participants (e.g., parents, peers, or teachers), and to alterations in the broader environment (community, economy, etc.). Study of psychopathology in development is thus enriched by adopting a transactional approach (e.g., Sameroff \& Chandler, 1975) that examines changes in context over time and the effects of such changes on the course of development. We know, for example, that the onset or progression of psychological disorder in one family 
member is likely to influence patterns of relationships within the family system, which will create further effects on the disordered individual's mental health (e.g., Patterson \& Stouthamer-Loeber, 1984; Rutter, 1990). Similarly, transformations in family relations in response to normative developmental change (e.g., the onset of puberty) often have implications for the mental health of family members (Silverberg \& Steinberg, 1990). Four particular aspects of contextual change that are worthy of more systematic investigation in research on psychopathology may be highlighted.

First, the contexts of childhood broaden, differentiate, and deepen with age, as children move from infancy through adolescence. Contexts broaden with development when they grow distally, into wider arenas of the child's external world. Differentiation occurs when a set of existing relationships disaggregates into subsets of functionally distinct social contexts. At high school entry, for example, a young person's early peer group typically redistributes itself into new and often unpredictable clusters of friendships and alliances. A deepening of contextual influences refers to change, over time, in the functions of social contexts, from those addressing basic, primal needs, such as protection and nutrition, to those filling more complex, elaborated needs, such as emotional regulation and interpersonal support. While contextual influences in early infancy, for example, are dominated by biological imperatives in the dyadic, caregiver-infant relationship, the broader family system takes on greater salience later in the 1st year of life as an influence on developmental outcomes (Belsky \& Rovine, 1988). As the child matures, the relevant contexts expand to include childcare and school settings (in early childhood), peer groups and neighborhoods (in elementary school), work and extracurricular settings (in adolescence), as well as broader influences derived from the surrounding culture and society. The roles and effects of such contexts change with development as well, becoming richer and more differentiated in their interactions with the child.

The broadening and deepening of developmentally relevant contexts over time does not imply that salient settings during early periods of development necessarily or uniformly wane in influence. For example, although peer groups become increasingly important during the transition to early adolescence, the family's influence remains as strong in adolescence as it was in early and middle childhood. Nor is it the case that relevant contexts broaden over the entire life cycle. After late adolescence, the relevant context for the development of psychopathology probably contracts, as individuals narrow their choices and limit the settings in which they spend their time. Research on contextual influences on psychopathology, with its focus on the family system, has not paid sufficient attention to the expanding and evolving social worlds of the child and their influences on development (Rubin, Hymel, Mills, \& Rose-Krasnor, 1991). Especially needed are more studies of children as they make transitions into increasingly complex and differentiated settings, such secondary school or part-time employment.

Second, the contexts of normal and pathological development shift in response to psychological and physical changes in the child over time. Transformations in family and peer relations and in classroom interactions take place, at least in part, in response to the child's development and maturation (Brown, 1990; Eccles et al., 1993; Steinberg, 1990). Other changes in interpersonal relations may occur specifically in response to the early emergence of psychopathology (e.g., Patterson, 1986). In addition to examining static features of contexts that contribute to the development of childhood disorders, future research is needed to investigate how patterns of psychopathology emerge, are consolidated, or remit as settings change in response to the child's behavior. Far more research has focused on contextual responses (in the family, peer group, or classroom) to children's externalizing problems (e.g., Cairns \& Cairns, 1994; Patterson, 1982) than on contextual responses to internalizing problems. Not only should researchers continue to ask how family relationships affect child anxiety and depression (e.g., Rutter, 1990); studies are also needed on how internalizing behavior on the part of the child affects family relationships. 
Third, children's contexts also change following changes in a setting's other participants. A few studies of such contextual changes and their implications for psychopathology have been conducted (e.g., research on the developmental effects of parental depressive episodes) (Dawson, Hessl, \& Frey, 1994; Hammen, Burge, Burney, \& Adrian, 1990a; Rutter, 1990) and parental alcoholism (Chassin, Rogosch, \& Barrera, 1991), but much more systematic work is needed. Especially important will be research that examines these changes as dynamic processes (e.g., studies of the impact of changes in parental depressive symptomatology on children's well-being, as opposed to studies comparing children of depressed versus nondepressed parents). Very little is currently known, for example, about the impact of parental psychological development on child well-being, about the relation between childhood psychopathology and changes in peer group relationships, or about changes in teachers' behavior and children's concomitant responses.

Finally, a context may broaden, differentiate, or deepen in reaction to events within the broader ecology. As Elder and others have eloquently pointed out (e.g., Elder, van Nguyen, \& Caspi, 1985; McLoyd, 1990b) families often change in structure and function in response to changing economic conditions. Similarly, the behavior of peer groups may change as a consequence of shifts in community crime rates or adult supervision (e.g., Sampson \& Laub, 1994). Schools may respond to changes in educational policies or practices. Although such changes may place severe adaptive demands on children and adults, research on how alterations in the broader environment affect the development of psychopathology is surprisingly sparse.

Recommendations. Future studies could be enriched by considering and measuring the ways in which social contexts and their effects on child psychopathology change over time in response to dynamic, developmental factors, such as

- the child's age and changing developmental status,
- the emergence of behavior problems and other early signs of mental disorder in the child,

- the presence or emergence of psychopathologic conditions in other members of the child's social contexts,

- dynamic changes in the breadth or roles of particular social contexts, and

- secular changes in the characteristics of the broader social ecology.

\section{Proposition 3: Contexts and children are mutually determining}

Individual developmental trajectories are responsive to children's experiences within the multiple contexts of culture, community, and family. Even at the cellular level, however, complex biological systems have been observed to change states in accord with the broader environments in which such systems operate (Fentress, 1991). At a much higher level of organization, the cultural context of childhood exerts important influences on childrens acquisition and use of language, their adoption of gender-specific roles, their attribution of meaning to life experience, and their incremental construction of a coherent worldview (Mead, 1961; Minturn \& Lambert, 1964; Super \& Harkness, 1980). Children growing up in economically blighted urban communities, for example, have futures that are clearly jeopardized by the poverty of early life experiences (Adler et al., 1994; Parker, Greer, \& Zuckerman, 1988). Abusive family settings create lifelong emotional and behavioral difficulties (Andrews, Valentine, \& Valentine, 1995; Fox \& Gilbert, 1994), while supportive parents can positively influence the structure and affective coloring of a child's convictions about the world (Boyce, 1985). At multiple levels of social organization, the contexts and settings in which children are reared wield powerful influences on the direction, course, and trajectory of developmental change.

Generally less well recognized, however, are the equally important, reciprocal ways in which children influence, interpret, choose and construct their own social contexts. In so 
doing, children play an active role in shaping their own development (Lerner \& BuschRossnagel, 1981; Sameroff, 1983). A growing body of infancy research, for example, suggests that early behavior serves to regulate interpersonal interactions in order to achieve a communicative and nurturant reciprocity with the parent (Gianino \& Tronick, 1988). In the course of interactions with their mothers, infants play an active role in achieving such reciprocity through differential responses to mothers, fathers, and strangers (Dixon et al., 1981), through contingencies in vocalization and smiling (Mayer \& Tronick, 1985), and through specific behaviors capable of modifying parental responses (Beebe, Jaffe, Feldstein, Mays, \& Alson, 1985). As noted by Gianino and Tronick (1988), "This affords the infant significant communicative power, particularly with a sensitive and responsive partner, enabling him to initiate, modify, and maintain the exchange."

Beyond infancy, children continue to modify and select their environments. Beginning with Bell's early paper (Bell, 1968) questioning the unidirectionality of effects in studies of child socialization, a variety of investigators have produced strong evidence of children's and adolescents' influences on the character of their social environments (e.g., Lytton, 1980). As developed further by Scarr and McCartney (1983), child effects on social contexts are produced through at least two identifiable mechanisms. First, evocative child-context effects result from the differential responsivity of social environments to children of different temperaments and personalities. Thus, friendly, happy babies are more likely than irritable, difficult babies to evoke positive and stimulating responses from their families and other social settings. Second, active child-context effects result from the process of niche-picking: the growing capacity of the child for choosing or selectively engaging those environments or aspects of environments most pleasing, affirming, or comforting, given the temperamental or personality characteristics of the individual child. For example, children with the 7-repeat allele of the dopamine receptor gene DRD4, a fixed marker for ADHD and novelty seeking behav- ior, may have more frequent exposures to chaotic homes or unruly peers. Plausible accounts for such gene-context correlations include the possibilities that children with the DRD4 marker gene might elicit less effective parental supervision or may select more antisocial peers (Plomin \& Rutter, in press).

As described by Hinde (1992) and Sameroff (1983), there is continuous interplay between features of the child and aspects of the social context in which the child is raised. This bidirectional transaction of contextupon-child and child-upon-context results in a continuous, mutually influential exchange between the developing individual and his or her social and physical environments. Child psychopathology research would benefit greatly, we believe, from efforts to move beyond the positions of individual constructivism and social determinism, to embrace a vision of dynamic interplay between an active, transforming child and the child's powerful but pliable social contexts. Such a vision has been more often apparent within research on normative aspects of child and adolescent development than in studies of psychopathology.

Less apparent or resolved on the basis of existing evidence are two aspects of these dynamic, transactional effects: first, the modalities of influence in both directions (i.e., the means by which contextual experience and child characteristics are mutually constructed), and second, the relative strength or importance of child $\rightarrow$ environment effects versus environment $\rightarrow$ child effects. As examples of the first of these dilemmas, the mental health effects of socioeconomic status and parental depression are well recognized, yet the actual means by which poverty or maternal depression affect psychopathological processes in children remain largely obscure (Adler, Boyce, Chesney, Folkman, \& Syme, 1993; Offord \& Fleming, 1995). Consistent associations have been demonstrated between child psychopathology and both family economic disadvantage (Offord, 1990) and parental affective disorders (Leckman, Weissman, \& Merikangas, 1985; Merikangas, Prusoff, \& Weissman, 1988), but hypotheses regarding the pathways through which these associations arise have only recently been tested. Candidate media- 
tors include the poor quality of mother-child interactions (Dawson, 1994; Hammen, Burge, \& Stansbury, 1990a; Harnish, Dodge, \& Valente, 1995), a lack of maternal warmth (Dodge, Pettit, \& Bates, 1994), or marital discord and family dysfunction (Lipman, Offord, \& Boyle, 1994). Parenting style and social referencing are two other mechanisms through which context may influence aspects of social and emotional development (Darling \& Steinberg, 1993; Hinde, 1992). The young of both human and nonhuman primates utilize the responses of trusted others (e.g., parents) to signal appropriate reactions to emotionally evocative events. While some of the mechanisms through which social contexts exert their effects have been explored, much less is understood about the ways in which individual differences among children produce developmentally salient effects on social environments.

Although some debate has centered upon the relative magnitudes of contextual versus child effects, it is increasingly clear that development and psychopathology are always the products of both organism and context. Past views almost undoubtedly erred in ascribing too much potency to environmental effects. As noted by Plomin and Rende (1991), for example, monozygotic twins reared together are as much alike on IQ as the same person measured twice, and twins reared in different families are only slightly less similar. Such observations led Scarr (1992) to conclude that "ordinary differences between families have little effect on children's development, unless the family is outside of a normal developmental range." Baumrind (1993), on the other hand, has argued that, even within a normative range of parenting practices, skills such as persuasive communication, contingent reinforcement, and monitoring produce powerful effects on developmental endpoints.

Rejecting the predominance of either genetic or contextual influences, Reiss et al. (1991) point out that, while there is irrefutable evidence of hereditary effects on the development of psychopathology, no studies have indicated that genetic factors account entirely for differences between ill and well individu- als. The genetic data themselves thus suggest a role for experiential influence. Further, genetic studies indicate that the most important of the contextual effects are those that are different for different siblings in the same family (i.e., the nonshared environmental effects). Environmental influences on psychopathologic disorders generally operate in the direction of making children from the same family different, as opposed to similar. Finally, children are, without question, much more than the products of their assembled genomes, and a child's interpretation and assignment of meaning to contextual experiences may alter profoundly the dynamic interchange between child and social context. Siblings who have different perceptions of their family environments (setting aside whether the psychologically relevant environments are objectively different) have different developmental outcomes as a consequence (Daniels, Dunn, Furstenberg, \& Plomin, 1985).

Recommendations. Future research on the joint and interactive influences of child-specific and contextual factors would benefit from considering

- measurement of both social contextual effects on the child and child effects on social context,

- modalities of such effects and the means through which children and contexts are mutually determining, and

- differentiation of genetically driven child effects and the individual child's values, dispositions, and propensities that lie, in a sense, between biology and context.

Proposition 4: A context's meaning to the child determines its effects on the child and arises from the context's ability to provide for fundamental needs

The developmental impact of social context is often, though not exclusively, mediated through a child's subjective reality. Optimal assessments of contextual influences must therefore take into account the child's construction and interpretation of contextual ex- 
perience. Lewin (1951) and later Bronfenbrenner (1986a; Bronfenbrenner \& Crouter, 1983) and Jessor (1981) argued, for example, that contexts should be described as perceived and experienced by the child. While there are objective aspects of children's environments that affect children directly (e.g., the impact of poverty and malnutrition on intellectual development), many environmental factors relevant to psychopathology are psychosocial in nature and open to individual interpretation. Jessor (1981) suggested that three different contexts - the demographic, social structural, and perceived-all differ in their proximity to the immediate, direct experience of the child. It is the perceived or interpretive social context, however, that lies closest to the child's actual experience of the world and is, of these three, most likely to effect psychopathological development. To paraphrase the Thomases' classic dictum, if children define the conditions under which they are reared as real, those conditions will be real in their consequences (Thomas \& Thomas, 1928).

Among the factors that influence the meaning a child assigns to a particular facet of social context are the child's developmental status, past experiences, and reference groups. Parental unemployment, for example, will likely have different effects on a younger versus older child, on a child who has previously experienced parental unemployment versus one who is experiencing it for the first time, and on a child who lives in a community with a high unemployment rate versus one in a community in which virtually all adults are working.

The importance of "meaning-making" in the development of psychopathology is wellillustrated in the work of Brown and colleagues (e.g., Brown \& Harris, 1989), who have argued that the effect of life stress on psychological well-being operates through the meaning of the event to the individual experiencing it. From this perspective, the prediction of psychopathology from contextual factors hinges on the researcher's ability to evaluate individual interpretation and experience. Prediction is less likely to be enhanced by an objective assessment of context, independent of the individual's perception.

Assessing a child's true subjective experi- ences within a given social context, however, is neither simple nor straightforward, and must often reach beyond the use of self-report measures. Although self-reports remain important and often singular windows into aspects of children's personal experiences, they can be contaminated by a variety of factors, including pressures for social desirability, difficulties in accurate recall, unconscious processes that lead to exaggeration, minimization or denial, and problems in verbal articulation. Researchers must therefore strive to find clever and original ways of assessing children's perceptions, drawing on methodological techniques used in clinical interviews, projective testing, experimental paradigms, and psychophysiological assessment.

Several recent studies illustrate innovative approaches to augmenting the insights garnered from simple self-reports. In a study designed to eliminate problems with children's verbal articulation of psychological constructs, Eder (1990) obtained information on preschoolers' self-conceptions. She hypothesized that standard methods used to elicit information from young children about themselves (i.e., interviews and self-report scales) were underestimating the sophistication of children's views. Rather than asking children to answer questions about their self-conceptions directly, Eder presented a series of displays involving two puppets who differed on specific personality dimensions. Based on children's answers, she was able to show that their self-conceptions were highly differentiated, internally coherent, and consistent over time.

A number of other researchers have followed Eder's lead and adapted her "puppet methodology" to the study of children's perceptions of the family environment and the links between their perceptions and psychological functioning. Such investigations have provided evidence that even preschool age children can provide reliable reports on different aspects of their family environments, and that such reports may be more highly correlated than are parents' reports with the objective assessments of trained observers (e.g., Ablow, Measelle, Cowan, \& Cowan, 1998; Sessa, Avenevoli, \& Steinberg, 1998).

Clever approaches to eliciting respondents' 
perceptions of their environment may be able to address some of the well-known problems inherent in self-report research. In one study constructed to overcome problems of social desirability in self-reports of parenting practices, Kagan (Kagan et al., 1986) used an experimental paradigm to examine social class differences in parental socialization techniques. Instead of asking parents to report directly on their behavior, Kagan presented audiotapes of experts giving child-rearing advice and varied the content of the advice along several key dimensions of child-rearing (e.g., discipline and acceptance). He then tested parents' recall of the taped messages. As hypothesized, significant socioeconomic differences were found in the patterns of recall, with individuals more likely to remember advice consistent with the predominant values of their social class.

Implicit in our interest in children's interpretations of social contexts is the idea that aspects of context critical to the development of psychopathology are those most closely related to children's most fundamental needs. Research on contextual factors in the development of psychological disorder might productively begin with an examination of what these needs are and the features of the environment most relevant to their satisfaction or frustration. In our view, the processes by which social contexts foster or undermine healthy development are those in which the child appraises the degree to which basic psychological needs are being met. While in infants and toddlers this process is largely nonverbal and preconscious, older children may be fully conscious of such appraisals and may be capable of verbalizing both their contents and conclusions. Even in an older child, however, meaning may be not simply cognitive, but may involve working models derived from preconscious processes (see, for example, Bowlby, 1988). Finally, it is important to note that positive meanings do not always arise from adequate provision for needs; a child may cling to an abusing parent, for example, despite active and malevolent disregard for the child's safety.

As Erikson (1963) and others in his tradition have noted, the child's fundamental needs reliably shift as he or she moves through the process of development. An infant's needs for basic life sustaining provisions, such as food and physical protection, give way in the preschool years to a young child's needs for adult constraints on behavior and access to fantasy and play. Similarly, needs in middle childhood for the support and guidance of trustworthy adults are transposed steadily and visibly into the adolescent's requirements for strong peer relationships, a sense of personal identity, and latitude for individuation from the family system. Social contexts thus generate meanings across all developmental periods, but the implications of such meanings change considerably with entry into new stages of motor, cognitive, emotional, and social development.

To some degree, the fundamental needs for healthy development will also vary from culture to culture and within cultures over time. On the other hand, certain core developmental needs are ubiquitous and may be required from a child's social context in some form, almost regardless of the individual culture and society. Examples of such needs might include those for predictability and consistency (Ainsworth, Blehar, Waters, \& Wall, 1978; Katz, 1971; Martin, 1975), warmth and support (Boyce, 1985; Cohen \& Wills, 1985; Parry \& Shapiro, 1986; Siegelman, 1966), encouragement of mastery (Bandura, 1995; Nolen-Hoeksema, Girgus, \& Seligman, 1986), physical safety (Garbarino \& Kostelny, 1993), and a sense of identity (Butler, 1975; Panak \& Garber, 1992; Zucker, 1990). A social context could thus be usefully evaluated in terms of the degree to which it meets or fails to meet critical developmental needs that play an important, collective role in the emergence or prevention of psychopathology.

Recommendations. Several methodological implications follow from this view of the importance of subjective meanings assigned to experiences within contexts. Among design features that may add substantially to the insights derived from study data are the following:

- collection of subjective as well as objective information about children's social contexts,

- innovative methods, beyond self-report, for 
assessing children's actual or likely subjective appraisals of their environments, and

- new methodologies that attend to the basic psychological and physical needs addressed by childhood social contexts.

Proposition 5: Contexts should be selected for assessment in light of specific questions or outcomes

In all studies of context and childhood psychopathology, it is important that the social environment be defined and measured according to the specific questions or outcomes under investigation. There is evidence, for example, that peer groups are more important than parents and families in influencing the adolescent behaviors of drug use and delinquency, while parents are more important than peers in influencing long-term values and future orientations (Kandel \& Lesser, 1972; Youniss, 1980). Although recent research has shown that there are often powerful interactions between peer and parent effects (e.g., Oswald \& Suss, 1994), the fact that one domain is usually dominant means that a researcher constrained to study a single context type might best select peer groups in a study of delinquency, and families in a study of educational and occupational aspirations. For all of the reasons enumerated above, however, studying more than a single contextual level and employing multidimensional views of those chosen would substantively advance research on social contexts.

A variation on this theme is that development itself is accompanied by shifts in the relative importance of children's various social contexts. For example, the relative importance of peer groups versus parents would increase in a longitudinal study, over the course of adolescence (Bowerman \& Kinch, 1959). Shifts in relevant contexts can also be seen in the phases through which problem behaviors progress. For example, while parental attitudes toward substance use are important determinants of adolescent drug use initiation, peer influences are dominant in affecting the course of continuing use (Kandel \& Andrews, 1987). In another example, the longitudinal work of Cowan and Cowan (Cowan, Cowan, Schulz, \& Heming, 1994) has documented the advent of powerful new contextual influences as children move from preschool to primary school settings. A complete developmental analysis of contextual influences would change its focus as it charts the effects of context on successive developmental phases (Bronfenbrenner, 1986b).

There is also evidence that within a particular level of context the most important dimensions differ depending on the outcome under investigation. For example, Furstenberg and Hughes (1995) have shown that parental warmth is a critical aspect of family context for predicting high school graduation, but that parental involvement and role modeling are more important aspects of family context in promoting stable work after the completion of schooling. A combination of these and other family context effects are important in understanding complex developmental outcomes, as such outcomes often require success in a number of domains with different contextual determinants. Successful transition to adulthood, for example, is associated with a multidimensional profile of outcomes that includes such factors as avoiding teen childbearing, completing school, establishing an intimate relationship with a partner, and developing stable membership in the labor force. Each of these outcomes is affected by somewhat different contextual influences, which should be studied in disaggregated form to understand the developmental processes involved in the larger outcome.

A more complex within-context problem for the researcher involves choosing the relevant level of aggregation to define a particular context for the outcomes of interest. Affiliation with a peer group that values success in school, for example, is known to be an important determinant of individual commitment and motivation at school (Ianni, 1983). As a result, the friendship network might be considered the most relevant level of aggregation for defining the school/peer context in a study of investment in school work. However, the general level of commitment and motivation among all classmates-not only the few who might share a child's high commitment to ed- 
ucation, but others in the class who also determine the speed and intensity with which the teacher can proceed-is likely to be more relevant in a study of learning. In a similar way, the appropriate level of aggregation used to define a neighborhood can differ according to the outcome of interest. If exposure to hazards is the focus, then the block might be the most relevant unit of analysis. If access to resources is the focus, then the area defining a police precinct, school district, or health department catchment area may be a more suitable unit of analysis. Finally, if a researcher is interested in peer influences in the neighborhood, then the area where youth congregate would be most appropriate, even if this area is geographically removed from the neighborhood in which the youth live. Because several of these influences may be of interest in a single study, accurate assessment of even a single level of context will, at times, require several different definitions tailored to the concepts the investigator seeks to operationalize.

The complexity associated with the fact that different aspects of context are relevant for different outcomes can be challenging, but theoretical considerations can often be helpful. For example, four classes of theory regarding the contextual effects of neighborhoods are (a) contagion theories, which suggest that peer influences can lead to the spread of behaviors by simple exposure; (b) collective socialization theories, which argue that neighborhood role models and behavior monitoring are more important than behavioral exposure; (c) competition theories, which emphasize the scarcity of resources within the neighborhood; and (d) relative deprivation theories, which suggest that neighborhood influences operate largely by creating standards, against which individuals evaluate their relative position (Jencks \& Mayer, 1990). Each category of theory hypothesizes different associations between neighborhood characteristics and child outcomes. Contagion and collective socialization theories, for example, suggest that exposure to middle class neighbors will benefit lower class children, while most versions of competition and relative deprivation theories suggest just the opposite (Brooks-Gunn, Duncan, Klebanov, \&
Sealand, 1993). Crane's (1991) contagion theory about the effects of neighborhood poverty and Wilson's (1987) theory of persistent poverty in inner-city neighborhoods both suggest that a critical mass of poverty (e.g., the percent of community residents living in poverty) is more important than exposure to middle class neighbors in producing school dropout and teenage childbearing. Research based on collective socialization theories, in comparison, would be more interested in evaluating options for positive role models, such as the number of middle class neighbors, since the proportion of families with higher incomes is a better predictor of adolescent outcomes than the proportion living in poverty (BrooksGunn et al., 1993).

Recommendations. Taken together, these observations indicate that constructs utilized as measures of contextual influence are best chosen to reflect the outcome or question of relevance within a given study design. Optimal selection of context measures will be most effectively served by investigators specifying and taking into account

- the most important level of the contextual domain,

- the salient dimensions within that domain,

- subjects' developmental stage, and

- theoretical assumptions underlying the search for contextual effects.

\section{Social context in light of developmental neurobiology}

Finally, there is growing recognition that early psychopathology is often the interactive product of adverse social contexts and learned or genetically determined organismic predispositions to disorder (Dawson et al., 1994; Jensen et al., 1991; Kagan, 1994). In light of new awareness for the individual, biological aspects of childhood mental disorders, it is imperative that research on the social contexts of psychopathology be grounded in and alert to the known effects of environment on neurobiologic processes and events. While better 
and more imaginative studies of contextual influences on clinical outcomes are crucial, major new insights may be derived from research examining experiential effects on the neural substrates of psychopathologic conditions.

An excellent example of how contextual influences may affect brain development is the set of processes guiding the formation of synapses. Though much of the fetal cortex is in place by the 5th month of human gestation, most cortical cells have not yet differentiated into mature, functional neurons. A differentiation phase begins and continues through the rest of pregnancy, and it is during this period that cell bodies, axons, and dendrites form and synapses are laid down. Greenough (Greenough \& Black, 1992) has proposed that there may be three separate mechanisms that account for synaptogenesis: experience-independent, experience-expectant, and experience-dependent processes. Together, the latter two of these mechanisms constitute the pathways of biological mediation through which aspects of context are transduced, or converted, into the neural imprints of environmental experience.

Experience-independent synaptogenesis refers to the formation of synapses without requirement for experiential input; an example is the development of taste buds on the tongue. Experience-expectant processes, on the other hand, are inductive processes that reduce the amount of information the genome must carry, when critical information is reliably present in the normal environment of the species. An example of an experience-expectant process is the development of vision, in which normal visual input is necessary for development of the ocular neuronal columns that fuse two retinal images, one from each eye, into a stereoscopic, three-dimensional image. If one eye is occluded during a sensitive developmental period, vision in that eye may not develop normally, because of aberrations in the formation of ocular columns in the occipital cortex. Finally, experience-dependent induction optimizes the individual's adaptation to specific, possibly unique features of the environment. An example is the information acquired by individual learning of new cognitive structures and information. Many aspects of emotional or social development likely also depend on unique aspects of child-environment interactions.

Greenough (Greenough \& Black, 1992) has argued that the neural substrate for the expectation of environmental influences is the unpatterned, temporary overproduction of synapses during the sensitive period, with a subsequent pruning back of unessential or inappropriate synapses (essentially a form of "neural Darwinism"; Edelman, 1987). The nervous system may ready itself for experience by overproducing synaptic connections, so that experience-related neural activity can select and preserve a functionally appropriate subset. We know, for example, that animals raised in complex (rather than stimulus impoverished) laboratory environments are cognitively superior on motivated learning tasks due to greater synaptic density and efficiency in several regions of the dorsal neocortex (Black, Sirevaag, Wallace, Savin, \& Greenough, 1989; Greenough, Juraska, \& Volkmar, 1979; Greenough, Madden, \& Fleischmann, 1972).

Available evidence supports the importance of environmental effects on brain development in both prenatal and postnatal life. In nonhuman primates, for example, Schneider and colleagues (Clarke \& Schneider, 1993; Clarke, Wittwer, Abbott, \& Schneider, 1994; Schneider, 1992) have demonstrated that even brief periods of prenatal stress can have serious and sustained effects on the infant monkey, including enhanced reactivity of the hypothalamic-pituitary-adrenocortical axis, abnormalities in neuromotor development, and alterations in behavioral responses to challenge.

Deprivation during the first several years of postnatal life has also been shown to affect a wide range of both behavioral and neurological functions (Pollitt \& Gorman, 1994). A common misconception is that deficiencies or adversities can influence brain maturation only in very early development. In fact, much of postnatal development beyond infancy is guided by activity- or experience-dependent principles involving strong contextual effects. 
Brain development depends critically on contextual input throughout the childhood years, and unless this input is of sufficient quality and appropriate in timing, much of normative development can go awry. The developmental effects of maternal depression, for example, may be due to the paucity or ill-timing of caretaking processes critical for the normative sequence of emotional and social development (Dawson et al., 1994).

Recommendations. Observations such as these indicate the importance of viewing social contexts as having not only psychological influences, but neurobiological effects as well. Emerging neuroscience suggests that social contexts in early life can exert critical influences on the course of developmental change in neural structures and processes and thereby augment or diminish risk for mental disorder. We have thus argued that researchers addressing contextual effects on psychopathological development should be knowledgeable of and attuned to the crucial and interactive influences of neurobiological processes. We would also affirm, however, the obverse: neuroscientists studying biological and genetic risk factors for psychopathology should attend, with new purpose, to the contextual influences that moderate or amplify biological risk.

\section{Conclusions}

Our objective in formulating these recommendations for research on social context in childhood psychopathology has been to assemble, within a single statement, the various principles we believe would strengthen studies of contextual influence on child mental health. The five presented propositions are our attempt to delineate these principles and the literatures that support their empirical validity. It is also our hope that a presentation of principles will benefit the field by stimulating further discourse on the character of contextual effects, by highlighting the areas where new or innovative research may be needed, and by guiding the selection of constructs and measures appropriate to such research.

The question might logically be asked, what value might this definitional and operational perspective on social context and its relation to childhood psychopathology offer at this time in the evolution of a developmental view of psychopathology? We believe that such a perspective could be useful at present for a variety of reasons. First, following the seminal work of Cassel (1976) on the health effects of social support, a large body of both observational and experimental evidence has now accumulated documenting the protective, salutary influences of supportive social interactions on a broad variety of health outcomes. While researchers have studied childhood social contexts intensively for many years, few efforts have yet been made to examine commonalities in approach, to search for areas of conceptual dissonance, or to identify themes in the findings from a variety of fields and laboratories. Second, much research to date has focused principally on either aspects of context that promote individual resilience or on those that enhance vulnerability. Less attention has been paid to issues such as the independence of risk and protective factors in social contexts or the degree to which they are simply conceptual mirror images of one another. Third, behavioral genetics and twin studies have emerged as powerful methodologic approaches to ascertaining the proportions of outcome variance assignable to genetic versus environmental forces. Behavioral genetics may provide an unprecedented view into the effects of contextual variation by eliminating the influences of biological inheritance. Finally, many investigators have become convinced that the most interesting and powerful accounts for developmental differences will be found in interactions between intrapersonal, biologic contexts and the character of the individual's multiple social contexts. The processes that govern development are far more complex, however, than those represented by the statistically interactive influences of child and environmental factors. What is now needed are studies that examine not simply the mathematical interactions among organismic and contextual variables, but the visible and experiential transactions between child and context. What is generally 
lacking in most current approaches to personenvironment interaction is a coherent and testable theory regarding how and under what conditions developmentally meaningful interactions take place.

In addition, a more elaborated perspective on childhood social context is needed because environments are, at least for the foreseeable future, more accessible and amenable to modification than are the genomes that determine, at least in part, the individual differences of salience to psychopathologic disorders. While genetic interventions may one day become a plausible approach to the most severe forms of psychopathology, preventive, contextual interventions will be regarded, in all likeli-

\section{References}

Ablow, J. C., Measelle, J. R., Cowan, P. A., \& Cowan, C. P. (1998). Young children's perceptions and processing of their parents' relationship: An evaluation of the marital relationship scales of the Berkeley Puppet Interview. Manuscript in preparation.

Adler, N. E., Boyce, W. T., Chesney, M. A., Cohen, S., Folkman, S., Kahn, R. L., \& Syme, S. L. (1994). Socioeconomic status and health: The challenge of the gradient. American Psychologist, 49(1), 15-24.

Adler, N. E., Boyce, W. T., Chesney, M. A., Folkman, S., \& Syme, S. L. (1993). Socioeconomic inequalities in health: No easy solution. Journal of the American Medical Association, 269(24), 3140-3145.

Ainsworth, M. D. S., Blehar, M. C., Waters, E., \& Wall, S. (1978). Patterns of attachment. Hillsdale, NJ: Erlbaum.

Andrews, B., Valentine, E. R., \& Valentine, J. D. (1995). Depression and eating disorders following abuse in childhood in two generations of women. British Journal of Clinical Psychology, 34, 37-52.

Baltes, P. B. (1997). On the incomplete architecture of human ontogeny: Selection, optimization, and compensation as foundation of developmental theory. American Psychologists, 52(4), 366-380.

Bandura, A. (1995). Self-efficacy in changing societies. New York: Cambridge University Press.

Bane, M. J., \& Ellwood, D. T. (1989). One fifth of the nation's children: Why are they poor? Science, 245, 1047-1053.

Baron, R., \& Kenny, D. (1986). The moderator-mediator variable distinction in social psychological research: Conceptual, strategic, and statistical considerations. Journal of Personality and Social Psychology, 51(6), 1173-1182.

Baumrind, D. (1993). The average expectable environment is not good enough: A response to Scarr. Child Development, 64, 1299-1317.

Becker, W. C. (1962). Developmental psychology. Annual Review of Psychology, 13, 1-34.

Beebe, B., Jaffe, J., Feldstein, S., Mays, K., \& Alson, D. (1985). Matching of timing: The application of an adult dialogue model to mother-infant vocal and hood, as the most effective and rational means of reducing the burden of the more prevalent childhood mental disorders. Interventions in all disciplines of medicine require empirical tests of their efficacies, and the design of preventive strategies involving social contexts will inevitably benefit from increased attention to the character of such contexts and their influences on emotional and behavioral development. It is our strong hope that new knowledge of children's social contexts will lead ultimately to effective preventive interventions and to a fuller and richer understanding of the developmental headwaters of childhood psychopathology.

kinesic interactions. In T. Field (Ed.), Infant social perception. Norwood, NJ: Ablex.

Bell, R. Q. (1968). A reinterpretation of the direction of effects in studies of socialization. Psychology Revue, 75, 81-95.

Belsky, J. (1988). Infant day care and socioemotional development: The United States. Journal of Child Psychology and Psychiatry, 29(4), 397-406.

Belsky, J., \& Rovine, M. J. (1988). Nonmaternal care in the first year of life and the security of infant-parent attachment. Child Development, 59, 157-167.

Black, J. E., Sirevaag, A. M., Wallace, C. S., Savin, M. H., \& Greenough, W. T. (1989). Effects of complex experience on somatic growth and organ development in rats. Developmental Psychobiology, 22(7), 727-752.

Blumenthal, S., \& Kupfer, D. (1988). Overview of early detection and treatment strategies for suicidal behavior in young people. Journal of Youth and Adolescence, 17, 1-24.

Bornstein, M. H. (1995). Form and function: Implications for studies of culture and human development. $\mathrm{Cul}$ ture Psychology, 1, 123-137.

Bowerman, C. E., \& Kinch, J. W. (1959). Changes in family and peer orientation of children between the 4th and 10th grades. Social Forces, 37, 296-211.

Bowlby, J. (1988). Developmental psychiatry comes of age. American Journal of Psychiatry, 145(1), 1-10.

Boyce, W. T. (1985). Social support, family relations and children. In S. Cohen \& L. Syme (Eds.), Social support and health. Reading, MA: Academic Press.

Boyce, W. T., Chesney, M., Alkon-Leonard, A., Tschann, J., Adams, S., Chesterman, B., Cohen, F., Kaiser, P., Folkman, S., \& Wara, D. (1995). Psychobiologic reactivity to stress and childhood respiratory illnesses: Results of two prospective studies. Psychosomatic Medicine, 57, 411-422.

Brody, G., Stoneman, Z., Flor, D., McCrary, C., Hatings, L., \& Conyers, O. (1994). Financial resources, parent psychological functioning, parent co-caregiving, and early adolescent competence in rural two-parent African-American families. Child Development, 65, 590605 . 
Bronfenbrenner, U. (1979). The ecology of human development: Experiments by nature and design. Cambridge, MA: Harvard University Press.

Bronfenbrenner, U. (1986a). Ecology of the family as a context for human development: Research perspectives. Developmental Psychology, 22(6), 723-742.

Bronfenbrenner, U. (1986b). Recent advances in research on the ecology of human development. In R. K. Siblersisen (Ed.), Development as Action in Context (pp. 287-309). New York: Springer-Verlag.

Bronfenbrenner, U., \& Crouter, A. C. (Eds.). (1983). The evolution of environmental models in developmental research (4th ed., Vol. 1). New York: Wiley.

Brooks-Gunn, J., Duncan, G., \& Aber, L. (1995). Neighborhood influences on child and adolescent development. New York: Russell Sage Foundation.

Brooks-Gunn, J., Duncan, G. J., Klebanov, P. K., \& Sealand, N. (1993). Do neighborhoods influence child and adolescent development? American Journal of Sociology, 99, 353-395.

Brown, B. (1990). Peer groups. In S. Feldman \& G. Elliott (Eds.), At the threshold: The developing adolescent (pp. 171-196). Cambridge, MA: Harvard University Press.

Brown, G. W., \& Harris, T. O. (1989). Life events and illness. New York: Guilford Press.

Butler, D. O. (1975). Psychotherapy: Implications of a black consciousness model. Psychotherapeutic Theory and Research Practice, 12, 407-411.

Cairns, R., \& Cairns, B. (1994). Lifelines and risks: Pathways of youth in our time. New York: Cambridge University Press.

Cassel, J. (1976). The contribution of the social environment to host resistance. American Journal of Epidemiology, 104, 107-123

Chassin, L., Rogosch, F., \& Barrera, M., Jr. (1991). Substance use and symptomatology among adolescent children of alcoholics. Journal of Abnormal Psychology, 100, 449-463.

Children's Defense Fund. (1995). The state of America's children: 1995. Washington, DC: Children's Defense Fund.

Cicchetti, D. (1993). Developmental psychopathology: Reactions, reflections, projections. Developmental Review, 13, 471-502.

Cicchetti, D., \& Richters, J. E. (1997). Examining the conceptual and scientific underpinnings of research in developmental psychopathology. Development and Psychopathology, 9(2), 189-191.

Cicchetti, D., \& Tucker, D. (1994). Development and self-regulatory structures of the mind. Development and Psychopathology, 6, 533-549.

Clarke, A. S., \& Schneider, M. L. (1993). Prenatal stress has long-term effects on behavioral responses to stress in juvenile rhesus monkeys. Developmental Psychobiology, 26(5), 293-304.

Clarke, A. S., Wittwer, D. J., Abbott, D. H., \& Schneider, M. L. (1994). Long-term effects of prenatal stress on HPA axis activity in juvenile rhesus monkeys. Developmental Psychobiology, 27, 257-270.

Cohen, S., \& Wills, T. A. (1985). Stress, social support, and the buffering hypothesis. Psychology Bulletin, 98, 310-357.

Cole, M. (1992). Context, modularity, and the cultural constitution of development. In L. T. Winegar \& J. Valsiner (Eds.), Children's Development Within Social Context. Hillsdale, NJ: Erlbaum.

Cole, M. (1995). The supra-individual envelope of devel- opment: Activity and practice, situation and context. In J. J. Goodnow, P. J. Miller, \& F. Kessel (Eds.), Cultural practices as contexts for development (Vol. 67). San Francisco: Jossey-Bass.

Conger, R., Ge, X., Elder, G., Jr., Lorenz, F., \& Simons, R. (1994). Economic stress, coercive family process, and developmental problems of adolescents. Child Development, 65, 541-561.

Cowan, P. A., Cowan, C. P., Schulz, M. S., \& Heming, G. E. B. (Eds.). (1994). Prebirth to preschool family factors in children's adaptation to kindergarten. In R. Parke \& S. G. Kellam (Eds.), Exploring family relationships with other social contexts. Hillsdale, NJ: Erlbaum.

Crane, J. (1991). The epidemic theory of ghettos and neighborhood effects on dropping out and teanage childearing. American Journal of Sociology, 96, 1226-1259.

Cummings, E., Ballard, M., El-Sheikh, M., \& Lake, M. (1991). Resolution and children's responses to interadult anger. Developmental Psychology, 27, 462-470.

Daniels, D., Dunn, J., Furstenberg, F., Jr., \& Plomin, R. (1985). Environmental differences within the family and adjustment differences within pairs of adolescent siblings. Child Development, 56, 764-774.

Darling, N., \& Steinberg, L. (1993). Parenting style as context: An integrative model. Psychology Bulletin 113(3), 487-496.

Dawson, G. (1994). Development of emotional expression and emotion regulation in infancy: Contributions of the frontal lobe. In G. Dawson \& K. Fischer (Eds.), Human Behavior and the Developing Brain. New York: Guilford Press.

Dawson, G., Hessl, D., \& Frey, K. (1994). Social influences on early developing biological and behavioral systems related to risk for affective disorder. Development and Psychopathology, 6, 759-779.

Dishion, T., Patterson, G., Stoolmiller, M., \& Skinner, M. (1991). Family, school, and behavioral antecedents to early adolescent involvement with antisocial peers. Developmental Psychology, 27, 172-180.

Dixon, S. D., Yogman, M., Tronick, E., Adamson, L., Als, H., \& Brazelton, T. B. (1981). Early infant social interaction with parents and strangers. Journal of the American Academy of Child Psychiatry, 20, $32-52$.

Dodge, K. A., Pettit, G. S., \& Bates, J. E. (1994). Socialization mediators of the relation between socioeconomic status and child conduct problems. Child Development, 65, 649-665.

Eccles, J. S., Midgley, C., Wigfield, A., Buchanan, C. M., Reuman, D., Flanagan, C., \& MacIver, D. (1993). Development during adolescence: The impact of stage-environment fit on young adolescents' experiences in schools and in families. American Psychology, 48(2), 90-101.

Edelman, G. M. (1987). Neural Darwinism: The theory of neuronal group selection. New York: Basic Books.

Eder, R. (1990). Uncovering young children's psychological selves: Individual and developmental differences. Child Development, 61, 849-863.

Eisenberg, L. (1995). The social construction of the brain. American Journal of Psychiatry, 152, 1563-1575.

Elder, G., Jr., \& Ardelt, M. (1992). Families adapting to economic pressure: Some consequences for parents and adolescents. Paper presented at the Society for Research on Adolescence, Washington, DC.

Elder, G. H., Jr., van Nguyen, T., \& Caspi, A. (1985). 
Linking family hardship to children's lives. Child Development, 56, 361-375.

Erikson, E. H. (1963). Childhood and society. New York: Norton.

Faris, R., \& Dunham, H. (1939). Mental disorders in urban areas. Chicago: University of Chicago Press.

Farrington, D., \& West, D. (1991). The Cambridge study in delinquent development: A long-term follow-up of 411 London males. In H. Kerner \& G. Kaiser (Eds.), Criminality: Personality, behavior, and life history (pp. 115-138). New York: Springer-Verlag.

Fauber, R., Forehand, R., McCombs, A., \& Wierson, M. (1990). A mediational model of the impact of marital conflict on adolescent adjustment in intact and divorced families: The role of disrupted parenting. Child Development, 61, 1112-1123.

Fentress, J. C. (1991). Analytical ethology and synthetic neuroscience. In P. Bateson (Ed.), The development and integration of behaviour (pp. 77-120). Cambridge: Cambridge University Press.

Fitzpatrick, K. (1993). Exposure to violence and the presence of depression among low-income, AfricanAmerican youth. Journal of Clinical and Consultative Psychology, 61, 528-531.

Fox, K. M., \& Gilbert, B. O. (1994). The interpersonal and psychological functioning of women who experienced childhood physical abuse, incest, and parental alcoholism. Child Abuse \& Neglect, 18(10), 849-858.

Frank, D. A., Zuckerman, B. S., Amaro, H., Aboagye, K., Bauchner, H., Cabral, H., Fried, L., Hingson, R., Kayne, H., Levenson, S. M., Parker, S., Reece, H., \& Vinci, R. (1988). Cocaine use during pregnancy: Prevalence and correlates. Pediatrics, 82(6), 888-895.

Furstenburg, F. F. J., \& Hughes, M. E. (1995). Social capital and successful development among at-risk youth. Journal of Marriage and Family, 57, 580-592.

Garbarino, J., \& Kostelny, K. (1993). Children's response to war: What do we know? In A. Leavitt \& N. A. Fox (Eds.), The psychological effects of war and violence on children. Hillsdale, NJ: Erlbaum.

Garmezy, N., Masten, A. S., \& Tellegen, A. (1984). The study of stress and competence in children: A building block for developmental psychopathology. Child Development, 55, 97-111.

Gianino, A., \& Tronick, E. Z. (1988). The mutual regulation model: The infant's self and interactive regulation and coping and defensive capacities. In T. M. Field, P. M. McCabe, \& N. Schneiderman (Eds.), Stress and coping across development (p. 264). Hillsdale, NJ: Erlbaum.

Goldsmith, H. H., Gottesman, I. I., \& Lemery, K. S. (1997). Epigenetic approaches to developmental psychopathology. Development and Psychopathology, 9(2), 365-387.

Greenough, W. T., \& Black, J. E. (1992). Induction of brain structure by experience: Substrates for cognitive development. In M. R. Gunnar \& C. A. Nelson (Eds.), Developmental Behavioral Neuroscience (Vol. 24). Hillsdale, NJ: Erlbaum.

Greenough, W. T., Juraska, J. M., \& Volkmar, F. R. (1979). Maze training effects on dendritic branching in occipital cortex of adult rats. Behavioral and Neural Biology, 26, 287-297.

Greenough, W. T., Madden, T. C., \& Fleischmann, T. B. (1972). Effects of isolation, dailing handling, and enriched rearing on maze learning. Psychonomic Science, 27, 279-280.

Hammen, C., Burge, D., Burney, E., \& Adrian, C. (1990).
Longitudinal study of diagnoses in children of women with unipolar and bipolar affective disorder. Archives of General Psychiatry, 47(12), 1112-1117.

Hammen, C., Burge, D., \& Stansbury, K. (1990). Relationship of mother and child variables to child outcomes in a high-risk sample: A causal modeling analysis. Developmental Psychology, 26, 24-30.

Harnish, J. D., Dodge, K. A., \& Valente, E. (1995). Mother-child interaction quality as a partial mediator of the roles of maternal depressive symptomatology and socioeconomic status in the development of child behavior problems. Child Development, 66, 739-753.

Harris, J. R. (1995). Where is the child's environment? A group socialization theory of development. Psychology Review, 102(3), 458-489.

Hiday, V. A. (1995). The social context of mental illness and violence. Journal of Health and Social Behavior, $36,122-137$.

Hinde, R. A. (1992). Developmental psychology in the context of other behavioral sciences. Developmental Psychology, 28(6), 1018-1029.

Ianni, F. A. J. (1983). Home, school, and community in adolescent education. [City unknown]: Clearinghouse on Urban Education.

Institute of Medicine. (1989). Research on children and adolescents with mental, behavioral, and developmental disorders: Mobilizing a national initiative. Washington, DC: National Academy of Sciences.

Jencks, C., \& Mayer, S. E. (1990). The social consequences of growing up in a poor neighborhood. In L. E. J. Lynn \& M. G. H. MaGeary (Eds.), Inner-city poverty in the United States. Washington, DC: National Academy Press.

Jensen, P. S., Koretz, D., Locke, B. Z., Schneider, S., Radke-Yarrow, M., Richters, J. E., \& Rumsey, J. M. (1993). Child and adolescent psychopathology research: Problems and prospects for the 1990s. Journal of Abnormal Child Psychology, 21(5), 551-580.

Jensen, P. S., Richters, J., Ussery, T., Bloedau, L., \& Davis, H. (1991). Child psychopathology and environmental influences: Discrete life events versus ongoing adversity. Journal of the American Academy of Child and Adolescent Psychiatry, 30, 303-309.

Jessor, R. (1981). The perceived environment in psychological theory and research. In D. Magnusson (Ed.), Toward a psychology of situations: An interactional perspective. Hillsdale, NJ: Erlbaum.

Jessor, R. (1993). Successful adolescent development among youth in high-risk settings. American Psychology, 48(2), 117-126.

Kagan, J. (1994). Galen's prophecy. New York: Basic Books.

Kagan, J. (1997). Conceptualizing psychopathology: The importance of developmental profiles. Development and Psychopathology, 9(2), 321-334.

Kagan, J., Reznick, S., Davies, J., Smith, J., Sigal, H., \& Miyake, K. (1986). Selective memory and belief: A methodological suggestion. International Journal of Behavioral Development, 9, 205-218.

Kandel, D. B., \& Andrews, K. (1987). Processes of adolescent socialization by parents and peers. International Journal of Addictions, 22, 319-342.

Kandel, D. B., \& Lesser, G. L. (1972). Youth in two worlds. San Francisco: Jossey-Bass.

Katz, R. C. (1971). Interactions between the facilitative and inhibitory effects of a punishing stimulus in the control of children's hitting behavior. Child Development, 42, 1433-1466. 
Koop, C. E., \& Lundberg, G. D. (1992). Violence in America: A public health emergency. Journal of the American Medical Association, 267, 3076-3077.

Leckman, J. F., Weissman, M. M., \& Merikangas, K. R. (1985). Major depression and panic disorder. Psychopharmacological Bulletin, 21, 543.

Lerner, R., \& Busch-Rossnagel, N. (1981). Individuals as producers of their own development: A lifespan perspective. New York: Academic Press.

Lewin, K. (1951). Field theory in social science: Selected theoretical papers. New York: Harper \& Row.

Lewinsohn, P., Rohde, P., Seeley, J., \& Fischer, S. (1993). Age-cohort changes in the lifetime occurrence of depression and other mental disorders. Journal of Abnormal Psychology, 102, 110-120.

Lipman, E. L., Offord, D. R., \& Boyle, M. H. (1994). Relation between economic disadvantage and psychosocial morbidity in children. Canadian Medical Association Journal, 151, 431.

Lytton, H. (1980). Parent-child interactions. New York: Plenum.

Martin, B. (1975). Parent-child relations. In F. D. Horowitz (Ed.), Review of child development research (Vol. 4). Chicago: University of Chicago Press.

Mayer, N., \& Tronick, E. (1985). Mother turn-giving signals and infant turn-taking in mother-infant interaction. In T. Field \& N. Fox (Eds.), Social perception in infants. Norwood, NJ: Ablex.

McCarthy, K., Lord, S., Eccles, J., Kalil, A., \& Furstenberg, F., Jr. (1992). The impact of family management strategies on adolescents in high risk environments. Paper presented at the Society for Research on Adolescence, Washington, DC.

McLoyd, V. (1990a). The declining fortunes of black children: Psychological distress, parenting, and socioemotional development in the context of economic hardship. Child Development, 61, 311-346.

McLoyd, V. (1990b). The impact of economic hardship on black families and children: Psychological distress, parenting, and socioemotional development. Child Development, 61, 311-346.

Mead, M. (1961). Coming of age in Somoa. New York: New American Library.

Merikangas, K. R., Prusoff, B. A., \& Weissman, M. M. (1988). Parental concordance for affective disorders: Psychopathology in offspring. Affective Disorders, $15,279$.

Miller, N., Cowan, P., Cowan, C., Hetherington, E., \& Clingempeel, W. (1993). Externalizing in preschoolers and early adolescents: A cross-study replication of a family model. Developmental Psychology, 29, 3-18.

Minturn, L., \& Lambert, W. (1964). Mothers of six cultures. New York: Wiley.

Minuchin, S. (1974). Families and family therapy. Cambridge, MA: Harvard University Press.

Nelson, C., \& Bloom, F. (in press). Child development and neuroscience. Child Development.

Nolen-Hoeksema, S., Girgus, J., \& Seligman, M. E. (1986). Learned helplessness in children: A longitudinal study of depression, achievement, and explanatory style. Journal of Personality and Social Psychology, 51(2), 435-442.

Offord, D. R. (1990). Social factors in the aetiology of childhood disorders. In B. Tonge, G. Burrows, \& J. Werry (Eds.), Handbook of studies on child psychiatry (pp. 55-68). Amsterdam: Elsevier.

Offord, D. R., \& Fleming, J. E. (1995). Epidemiology. In M. Lewis (Ed.), Child and adolescent psychiatry: A comprehensive textbook (2nd ed.). Baltimore: Williams \& Wilkins.

Oswald, H., \& Suss, K.-U. (1994). The influence of parents and peers on misconduct at school: Simultanenous and synergistic effects. In R. K. Silbereisen \& E. Todt (Eds.), Adolescence in context: The interplay of family, school, peers, and work in adjustment (pp. 347-365). New York: Springer-Verlag.

Panak, W. F., \& Garber, J. (1992). Role of aggression, rejection, and attributions in the prediction of depression in children. Development and Psychopathology, 4, 145-165.

Parker, S., Greer, S., \& Zuckerman, B. (1988). Double jeopardy: The impact of poverty on early child development. Pediatric Clinic of North America, 35(6), 1227-1240.

Parry, G., \& Shapiro, D. A. (1986). Social support and life events in working class women: Stress buffering or independent effects? Archives of General Psychiatry, 43, 315-323.

Patterson, G. (1986). Performance models for antisocial boys. American Psychologist, 41, 432-444.

Patterson, G., \& Stouthamer-Loeber, M. (1984). The correlation of family management practices and delinquency. Child Development, 55, 1299-1307.

Patterson, G. R. (1982). Coercive family processes. Eugene, OR: Castalia.

Petersen, A., Compas, B., Brooks-Gunn, J., Stemmler, M., Ey, S., \& Grant, K. (1993). Depression in adolescence. American Psychologist, 48, 155-168.

Plomin, R., \& Rende, R. (1991). Human behavioral genetics. Annual Review of Psychology, 42, 161-190.

Plomin, R., \& Rutter, M. (in press). Child development, molecular genetics, and what to do with genes once they are found. Child Development.

Pollitt, E., \& Gorman, K. S. (1994). Nutritional deficiencies as developmental risk factors. In C. A. Nelson (Ed.), Threats to optimal development: Integrating biological, psychological, and social risk factors (Vol. 27, pp. 121-144). Hillsdale, NJ: Erlbaum.

Reiss, D., Plomin, R., \& Hetherington, E. M. (1991). Genetics and psychiatry: An unheralded window on the environment. American Journal of Psychiatry, 148 283-291.

Richmond, J. (1990, May). Making the nineties the decade of the child. American Academy of Pediatrics News, 17.

Rubin, K., Hymel, S., Mills, R., \& Rose-Krasnor, L. (1991). Conceptualizing different developmental pathways to and from social isolation in childhood. In D. Cicchetti \& S. Toth (Eds.), Internalizing and externalizing expressions of dysfunction (pp. 91-122). Hillsdale, NJ: Erlbaum.

Rutter, M. (1990). Commentary: Some focus and process considerations regarding effects of parental depression on children. Developmental Psychology, 26, 60-67.

Rutter, M., Dunn, J., Plomin, R., Simonoff, E., Pickles, A., Maughan, B., Ormel, J., Meyer, J., \& Eaves, L. (1997). Integrating nature and nurture: Implications of person-environment correlations and interactions for developmental psychopathology. Development and Psychopathology, 9(2), 335-364.

Sameroff, A. J. (1983). Developmental systems: Contexts and evolution. In W. Kessen (Ed.), History, theory, and methods (4th ed., Vol. 1, pp. 237-294). New York: Wiley.

Sameroff, A. J., \& Chandler, M. J. (1975). Reproductive 
risk and the continuum of caretaking casualty. In $\mathrm{F}$ D. Horowitz, M. Hetherington, S. Scarr-Salapatek, \& G. Siegel (Eds.), Review of child development research (Vol. 4, pp. 187-243). Chicago: University of Chicago Press.

Sampson, R., \& Laub, J. (1994). Urban poverty and the family context of delinquency: A new look at structure and process in a classic study. Child Development, 65, 523-540.

Scarr, S. (1992). Developmental theories for the 1990s: Development and individual differences. Child Development, 63, 1-19.

Scarr, S., \& McCartney, K. (1983). How people make their own environments: A theory of genotype $\rightarrow$ environment effects. Child Development, 54, 424-435.

Schneider, M. L. (1992). Prenatal stress exposure alters postnatal behavioral expression under conditions of novelty challenge in rhesus monkey infants. Developmental Psychobiology, 25(7), 529-540.

Sessa, F. M., Avenevoli, S., \& Steinberg, L. (1998). The assessment of parent-child relations in the study of developmental psychopathology: A conceptual framework and methodological proposal. Manuscript in preparation.

Siegelman, M. (1966). Loving and punishing parental behavior and introversion tendences in sons. Child Development, 37, 985-992.

Silverberg, S. B., \& Steinberg, L. (1990). Psychological well-being of parents with early adolescent children. Developmental Psychology, 26(4), 658-666.

Solomon, J., \& Wallerstein, J. (1994). The consequences of divorce and changing family structures for the health and development of children. New York: Maternal and Child Health Bureau.

Sroufe, L. A. (1989). Pathways to adaptation and maladaptation: Psychopathology as developmental deviation. In D. Cicchetti (Ed.), Rochester Symposium on Developmental Psychopathology: Vol. 1. The emergence of a discipline (pp. 13-40). Hillsdale, NJ: Erlbaum.

Sroufe, L. A. (1997). Psychopathology as an outcome of development. Development and Psychopathology, 9(2), 251-268.

Stark, K., Humphrey, L., Cook, K., \& Lewis, K. (1990). Perceived family environments of depressed and anxious children: Child and maternal figures' perspec- tives. Journal of Abnormal Child Psychology, 18 527-547.

Steinberg, L. (1990). Autonomy, conflict, and harmony in the family relationship. In S. Feldman \& G. Elliot (Eds.), At the threshold: The developing adolescent (pp. 255-276). Cambridge, MA: Harvard University Press.

Steinberg, L., Catalano, R., \& Dooley, D. (1981). Economic antecedents of child abuse and neglect. Child Development, 52, 975-985.

Super, C., \& Harkness, S. (1980). Anthropological perspectives on child development, new directions for child development (Vol. 8). San Francisco: Jossey-Bass.

Thomas, W., \& Thomas, D. (1928). The child in America. New York: Knopf.

U.S. House of Representatives Select Committee on Children, Youth, and Families. (1989). U.S. children and their families: Current conditions and recent trends, 1989. Washington, DC: Author.

U.S. Department of Health and Human Services. (1990a). Child Health USA '90 (HRS-M-CH 90-1): Health Resources and U.S. Department of Health and Human Services Administration. Washington, DC: Author.

U.S. Department of Health and Human Services. (1990b) National Plan for Research on Child and Adolescent Mental Disorders (ADM publication No. 90-1683): Alcohol, Drug Abuse, and Mental Health Administration. Washington, DC: Author.

Weisz, J., Suwanlert, S., Chaiyasit, W., Weiss, B., Achenbach, T., \& Eastman, K. (1993). Behavioral and emotional problems among Thai and American adolescents: Parent reports for ages 12-16. Journal of Abnormal Psychology, 102, 395-403.

Wilson, W. J. (1987). The truly disadvantaged: The inner city, the underclass, and public policy. Chicago: University of Chicago Press.

Youniss, J. (1980). Parents and peers in social development: A Sullivan-Piaget perspective. Chicago: University of Chicago Press.

Zill, N., \& Schoenborn, C. A. (1990). Developmental, learning, and emotional problems: Health of our nation's children, United States, 1988. Washington, DC: National Center for Health Statistics.

Zucker, K. J. (1990). Psychosocial and erotic development in cross-gender identified children. Canadian Journal of Psychiatry, 35, 487-495. 